\title{
Noteworthy Articles of 2020
}

\author{
Rochita Venkataramanan ${ }^{1}$ \\ ${ }^{1}$ Department of Clinical Radiology, Apollo Hospitals, Chennai, Tamil \\ Nadu, India
}

J Gastrointestinal Abdominal Radiol ISGAR 2021;4:1-2.

The year 2020, despite its difficulties due to the coronavirus disease 2019 (COVID-19) pandemic, was a remarkable year for the Journal of Gastrointestinal and Abdominal Radiology (JGAR). JGAR's indexation in the Directory of Open Access Journals (DOAJ) within a short span of 3 years of its existence has been possible because of the effort and involvement of its authors, reviewers, and editors. It has been a proud moment for us and this year will always be special for JGAR.

The year 2020 was also fruitful for JGAR with a remarkable special issue on Pancreatic Imaging. Our guest editors Raju Sharma and Rajesh Arumugam did a remarkable job of guiding the authors and bringing out their absolute best in this issue.

The Post-Operative Pancreas Imaging, from this issue, illustrates the imaging findings during the early postoperative period as well as postsurgical complications in both acute and chronic postoperative settings. ${ }^{1}$

Another noteworthy article from the same issue reviewed imaging of pancreatic trauma with organization into suspected pancreatic injury with normal-appearing pancreas on computed tomography (CT), definite pancreatic injury on CT, and late presentation in pancreatic injury. ${ }^{2}$

The journal's second issue evaluated activity in Crohn's disease in the pediatric population with magnetic resonance enterography. ${ }^{3}$ The same issue carries an article on characterization of hepatic metastases with representative images and comprehensive discussions. This is an informative read with representative images. ${ }^{4}$

The journal saw an increase in the submission of manuscripts by mid-2020 and thus it was decided to bring out a supplementary issue. This issue has three remarkable original articles. Thambidurai et al assess the role of diffusion tensor imaging in the correlation between diffusion tensor parameters and the estimated glomerular filtration rate value in transplant kidneys with 3-Tesla magnetic resonance imaging. ${ }^{5}$

Anandan et al in their original research demonstrated that extra-pancreatic necrotic volume has a statistically significant correlation with outcome parameters as well as in predicting overall organ failure, whereas modified CT severity index had no significant correlation with the above-mentioned factors. ${ }^{6}$

The abdominal radiograph is a valuable resource and serves as a refresher for the various radiological signs on the plain X-ray of the abdomen. ${ }^{7}$

I wish our readers, authors, reviewers, and editors a happy new year and thank them for all of their valuable support. Let us pray and hope that we have left the COVID-19 pandemic behind us and are on the way to recovery. We look forward to 2021 with more exciting research articles, reviews, and most definitely another special issue.

Conflict of Interest

None declared.

\section{References}

1 Taher A, Mujtaba B, Ramani NS, Patel A, Morani AC. The postoperative pancreas imaging. J Gastrointest Abdominal Radiol 2020;3(1):87-98

2 Hemachandran N, Gamanagatti S. Imaging of pancreatic trauma-a clinical scenario-based approach. J Gastrointest Abdominal Radiol 2020;3(1):28-34

3 Radhakrishnan S, Chellathurai A, Sankaranrayanan S, Sankar D, Rajan S. Role of MR enterography in evaluation of disease activity in pediatric Crohn's disease: correlation between MR enterography and pediatric Crohn's Disease Activity Index Scores. J Gastrointest Abdominal Radiol 2020;3(2):118-125

4 Patil PG, Reddy P, Rawat S, Ananthasivan R, Sinha R. Multimodality approach in detection and characterization of hepatic metastases. J Gastrointest Abdominal Radiol 2020;3(2):163-180

\author{
Address for correspondence \\ Rochita Venkataramanan, MD, \\ DNB, DMRD, Department of Clinical \\ Radiology, Apollo Hospitals, No. 34, \\ Srinivasa Murthy Avenue, Off L. B. \\ Road, Adyar, Chennai 600020, \\ Tamil Nadu, India \\ (e-mail: rochitav@yahoo.com, \\ rochitav@gmail.com).
}

DOI https://doi.org/

$10.1055 / \mathrm{s}-0041-1727402$

ISSN 2581-9933
(C2021. Indian Society of Gastrointestinal and Abdominal Radiology. This is an open access article published by Thieme under the terms of the Creative Commons Attribution-NonDerivative-NonCommercial-License, permitting copying and reproduction so long as the original work is given appropriate credit. Contents may not be used for commercial purposes, or adapted, remixed, transformed or built upon. (https://creativecommons.org/licenses/by-nc-nd/4.0/). Thieme Medical and Scientific Publishers Pvt. Ltd. A-12, 2nd Floor, Sector 2, Noida-201301 UP, India 
5 Thambidurai S, Arunachalam VK, Rupa R, Sriman R. Role of diffusion tensor imaging in functional assessment of transplant kidneys at 3-Tesla MRI. J Gastrointest Abdominal Radiol 2020;3(S1) :S7-S14

6 Anandan RR, Patil S, Renganathan R, Varatharajaperumal RK, Ramasamy R, Arunachalam VK, Extra pancreatic necrotic volume: can it prognosticate acute necrotising pancreatitis-a prospective study. J Gastrointest Abdominal Radiol 2020;3(S1): S15-S21

7 Raut AA, Naphade PS, Maheshwari S. Abdominal radiograph. J Gastrointest Abdominal Radiol 2020;3(2):S22-S34 